\title{
Análisis faunístico del sitio Laguna de los Pampas (partido de Lincoln, región Pampeana). Aportes a los estudios de la subsistencia en el área Oeste de la Pampa Húmeda
}

\author{
María C. Álvarez*
}

Recibido:

8 de marzo de 2017

Aceptado:

9 de agosto de 2017

\section{Resumen}

Las investigaciones desarrolladas en los últimos años permitieron generar modelos sobre la subsistencia de los cazadores-recolectores que habitaron las distintas áreas de la región Pampeana durante el Pleistoceno final/Holoceno. Sin embargo, para el área Oeste, los datos sobre la dieta son aún escasos. En este trabajo se presentan los resultados del análisis del conjunto arqueofaunístico del sitio Laguna de los Pampas (partido de Lincoln, Buenos Aires), con el objetivo de evaluar las principales tendencias de la subsistencia. Asimismo, se pretende comparar los resultados con los modelos de dieta conocidos para otras áreas lindantes. La muestra de Laguna de los Pampas está conformada por 2.583 especímenes y cuenta con dos fechados correspondientes al Holoceno medio. A partir de los análisis realizados se pudo determinar la explotación de una importante diversidad de especies de distinto tamaño (Ntaxa $=9$ ), entre ellas: artiodáctilos, armadillos, roedores, carnívoros y aves. Los datos generados son coincidentes con el modelo propuesto para el área Interserrana para la primera mitad del Holoceno medio, momento en el cual se observa una dieta orientada hacia el consumo de los artiodáctilos, pero complementada con una amplia variedad de taxones.

Faunistic analysis of the Laguna de los Pampas site (Lincoln County, Pampean Region): Contributions to the study of subsistence in the Western Area of Humid Pampa

\footnotetext{
Abstract

Research conducted during the last decades has led to the development of models concerning the subsistence of hunter-gatherers that inhabited the different areas of the Pampean Region during the Late Pleistocene/Holocene. However, for the West area, the available data on diet is still limited. This paper presents the results of faunal analysis on an assemblage from the site of Laguna de los Pampas (Lincoln County, Buenos Aires). The aim is to evaluate the main subsistence trends. Furthermore, these

* Investigaciones Arqueológicas y Paleontológicas del Cuaternario Pampeano (INCUAPA), Facultad de Ciencias Sociales, Universidad Nacional del Centro de la Provincia de Buenos Aires (UNICEN) - CONICET. Av. Del Valle 5737 (CP B740oJWI) Olavarría, Buenos Aires, Argentina. E-mail: malvarez@soc.unicen.edu.ar
}

\section{Palabras clave}

\section{Zooarqueología} Tafonomía

Modelos de subsistencia Área Oeste

\section{Keywords}

Zooarchaeology Taphonomy Subsistence models Western area 
results were then compared against subsistence models generated for adjacent areas. There are 2,583 specimens dating to the Middle Holocene in the sample from Laguna de los Pampas. This analysis indicates the consumption of a wide range of differentsized animals (Ntaxa $=9$ ), including artiodactyls, armadillos, rodents, carnivores, and birds. The data corresponds to the subsistence model proposed for the Interserrana area during the first half of the Middle Holocene. This diet focused on the exploitation of artiodactyls, although complemented by a wide variety of different taxa.

\section{Introducción}

En las últimas décadas se han generado distintos modelos de subsistencia que describen los patrones en la dieta de los cazadores-recolectores que habitaron la Región Pampeana a lo largo del Pleistoceno final y del Holoceno (Gutiérrez y Martínez, 2008; Loponte, Acosta y Musali, 2006; Martínez y Gutiérrez, 2004; Miotti y Salemme, 1999; Politis y Salemme, 1990; Quintana y Mazzanti, 2001; entre otros). Dichos modelos han sido propuestos considerando siete unidades de investigación consensuadas en la subregión Pampa Húmeda, que se basan en características y similitudes fisiográficas y en la organización de los datos arqueológicos disponibles (Politis, 1984). En cada una de éstas unidades se cuenta con antecedentes de estudios acerca de la dieta, los cuales se han focalizado principalmente en las áreas Interserrana (e.g., Álvarez, 2014a; Bayón, Frontini y Vecchi, 2012; Massigoge, 2007; Messineo, 2011), Norte (e.g., Acosta, Loponte y Mucciolo, 2010, 2014), Depresión del Salado (e.g., Escosteguy, Salemme y González, 2012; Escosteguy, González y Frère, 2015), sistema serrano de Tandilia (e.g., Quintana y Mazzanti, 2001, 2010) y Sur (e.g., Martínez, 2008-2009; Stoessel y Martínez, 2014; Vecchi, Frontini y Bayón, 2013). Recientemente, han comenzado a desarrollarse algunos trabajos en el área de Ventania (Catella, 2014; Morales, 2015). Para el caso específico del área Oeste se cuenta con datos escasos y aislados acerca de la subsistencia. Se han realizado algunos análisis sobre los materiales superficiales provenientes del sitio Laguna Salalé, partido de Florentino Ameghino (Oliva, Algrain, Ávila y Gallego, 2004) y la localidad Laguna Arroyo Venado, partido de Guaminí (Oliva et al., 2015). En los últimos años se analizaron nuevos sitios, como Laguna Cabeza de Buey 2, partido de Bolívar (Scheifler y Messineo, 2016), La Susana 1 y Huencú Nazar, partido de Trenque Lauquen (Scheifler, Messineo y Antiñir, 2017) y, en cercanías del sitio presentado en este trabajo, Laguna El Doce, Departamento de General López (Cornaglia Fernández, 2014).

En este trabajo se presentan los resultados del análisis del conjunto arqueofaunístico del sitio Laguna de los Pampas (partido de Lincoln, provincia de Buenos Aires). El objetivo es evaluar las principales tendencias en la subsistencia a partir de esta muestra. De esta forma, se espera obtener nuevos datos acerca de la dieta en el área Oeste, así como compararlos con aquellos procedentes de áreas lindantes.

\section{Antecedentes del sitio Laguna de los Pampas}

En el año 2009 se efectuó un rescate arqueológico en el partido de Lincoln, en las orillas de una laguna innominada próxima a la localidad de Martínez de Hoz. Este surgió por la necesidad de recuperar materiales arqueológicos que habían quedado expuestos en la playa de la laguna producto de la erosión que sufrieron las barrancas por la acción del agua. Las actividades efectuadas durante estas tareas permitieron recuperar una gran cantidad y variedad de restos culturales, cuyo análisis ha arrojado valiosos resultados acerca de las ocupaciones de los cazadores-recolectores en el área (Politis, Messineo, González, Álvarez y Favier Dubois, 2012). En aquel momento se efectuaron tres fechados radiocarbónicos sobre los restos de este sitio, denominado Laguna de los Pampas (LLP, Figura 1). Estos indicaron que las ocupaciones tuvieron 


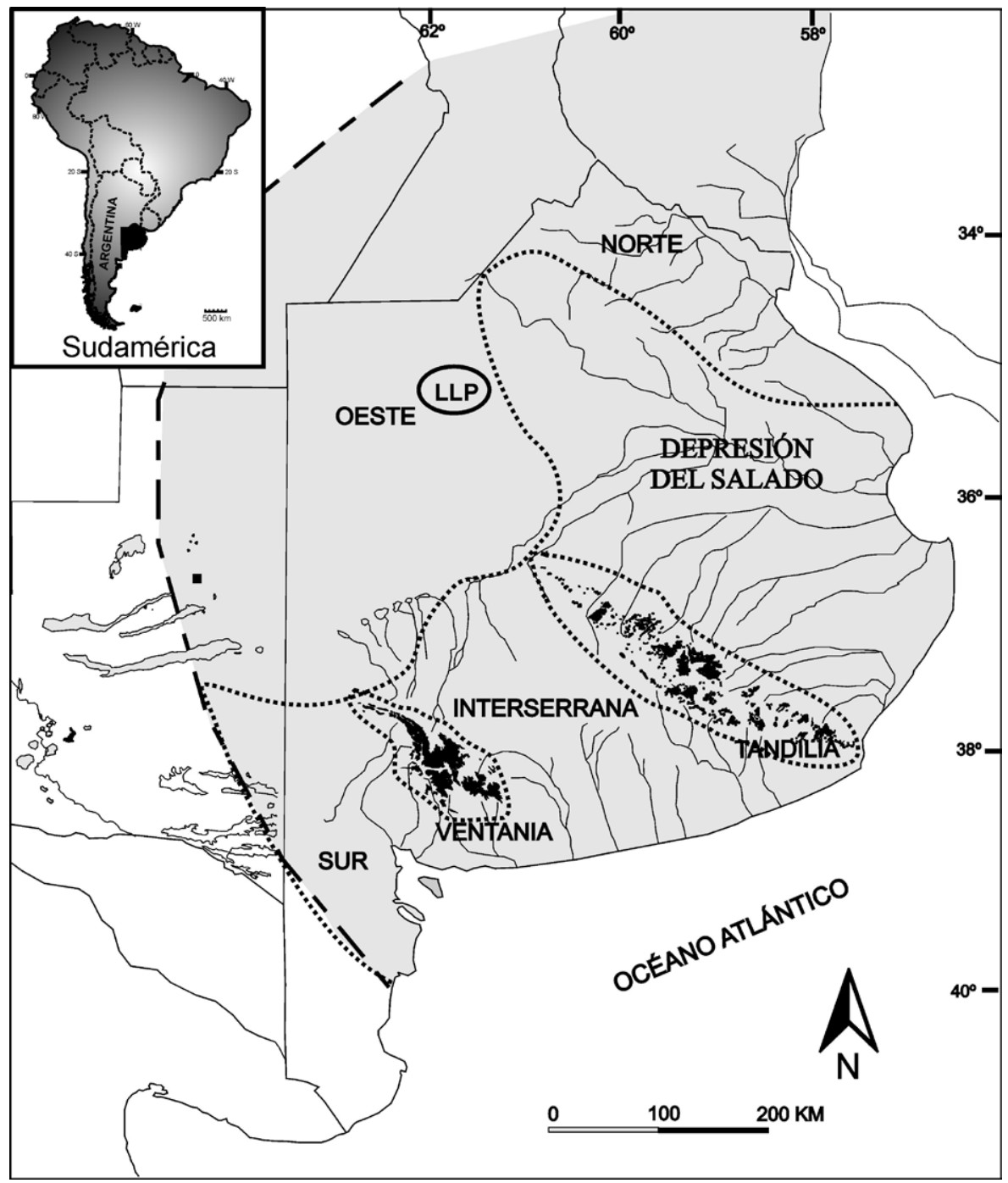

Figura 1. Subregión Pampa Húmeda (en gris) y ubicación de las áreas que la componen y del sitio Laguna de los Pampas.

lugar en el Holoceno temprano (8971 \pm 77 años AP -AA-90127- y $8835 \pm 83$ años AP -AA-93221-; restos humanos), medio (5684 \pm 61 años AP -AA-93220-; restos faunísticos) y tardío (cronología contextual; alfarería) (Menéndez et al., 2015; Politis et al., 2012, p. 470).

En el caso de la fauna, se analizaron 1.356 especímenes faunísticos de superficie (Sector 1), a partir de los cuales se pudo proponer la explotación de tres especies: guanaco, venado de las pampas y ñandú (Politis et al., 2012). Además, se llevó a cabo un estudio sobre los materiales óseos con evidencias tecnológicas (Álvarez, 2014b). Durante los años siguientes al rescate, se realizó una serie de sondeos en los perfiles de la laguna, en la zona donde se encontraron los materiales en superficie correspondientes al sitio LLP. En uno de estos sondeos se hallaron materiales en estratigrafía, por lo cual en marzo de 2015 se efectuaron trabajos de excavación a través de los que se plantearon seis cuadrículas $\left(6 \mathrm{~m}^{2}\right)$. Las tareas de campo permitieron recuperar una gran cantidad de restos culturales, principalmente artefactos líticos y fragmentos óseos de diversas especies animales. Hasta el momento se han excavado 25 niveles artificiales de $5 \mathrm{~cm}$ de espesor cada uno en los $6 \mathrm{~m}^{2}$ considerados. 
En cuanto a la estratigrafía, la descripción detallada del perfil del sitio puede encontrarse en Messineo, González y Álvarez (2017). En líneas generales, se observan cuatro unidades estratigráficas, definidas previamente para otros perfiles de la laguna. Los materiales arqueológicos se ubican la Unidad IV, la cual es interpretada como un horizonte $\mathrm{C}$, correspondiente a un depósito areno-limoso de color castaño claro, de origen eólico. Con respecto a la cronología, durante el año 2015 se enviaron a datar al NFS Arizona AMS Laboratory dos restos óseos de guanaco con evidencias de procesamiento, procedentes de distintos niveles de la excavación. Una de las dataciones, obtenida en la base de la secuencia, dio un fechado de $7024 \pm 45$ AP (AA-106728) y la otra, recuperada en la sección media, dio $5815 \pm 40$ AP (AA-106729) (Messineo et al., 2017).

\section{Materiales y métodos}

La muestra analizada comprendió el total de los materiales faunísticos recuperados en el sitio, procedentes tanto de planta como de cernidor, con excepción de los restos de microvertebrados correspondientes a anuros y roedores (menores a $1 \mathrm{~kg}$ de peso, Stahl, 1996). Además, se consideró el límite de $15 \mathrm{~kg}$ para diferenciar presas asignables a caza mayor o menor (Quintana y Mazzanti, 2010). En primera instancia, se llevó a cabo el análisis taxonómico y anatómico a partir del uso de colecciones de referencia localizadas en la Facultad de Ciencias Sociales (Olavarría, UNICEN). Se identificó el número de especímenes (NSP) agrupado en categorías taxonómicas, considerando los niveles de determinación alcanzados. Al momento de calcular los porcentajes de NISP por taxón se excluyeron las cáscaras de huevo y placas de dasipódidos, dado que constituyen la mayoría de la muestra y homogeneizarían los resultados. Por otro lado, en algunos casos el porcentaje del NISP se estimó por medio de la combinación de distintos niveles taxonómicos, agrupados por especie, género o incluso familia.

Para todos los taxones se utilizaron las medidas de número de especímenes óseos identificados por taxón (NISP) y número mínimo de individuos (MNI). Además, para el caso del guanaco se construyó el perfil de partes esqueletarias a partir del número mínimo de elementos (MNE), número mínimo de unidades anatómicas identificadas por taxón (MAU) y este mismo valor estandarizado (MAU\%) (Binford, 1978; Grayson, 1984; Klein y Cruz-Uribe, 1984; entre otros). La representación esqueletaria fue correlacionada estadísticamente (rho de Spearman) con el Índice de Utilidad de Carne de Guanaco (Borrero, 1990) modificado por Lyman (1992) y el Índice de Médula (Mengoni Goñalons, 1999). Para esta especie también se utilizaron medidas de intensidad y extensión de la fragmentación (NISP: MNE y Completitud \%, respectivamente) (Lyman, 1994; Wolverton, 2002).

Se llevó a cabo el análisis tafonómico de todos los especímenes óseos, con excepción de los osteodermos y los fragmentos de cáscara de huevo. Se consideró el ambiente de depositación y sedimentación, así como el relevamiento de las siguientes variables: meteorización, acción de roedores, de carnívoros y de raíces, presencia de manganeso, pisoteo, fracturas y abrasión sedimentaria (Behrensmeyer, 1978; Binford, 1981; Grayson, 1984; Gutiérrez y Kaufmann, 2007; Haynes, 1980; Johnson, 1985; Lyman, 1994; Olsen y Shipman, 1988; entre otros). En cuanto a la incidencia de procesos atricionales mediados por la densidad mineral ósea, se consideró la diferencia entre las proporciones de las epífisis proximal y distal (con bajos y altos valores de densidad mineral, respectivamente) de los elementos esqueletarios húmero y tibia (Binford, 1981; Marean y Ehrhardt, 1995).

Se relevaron evidencias de procesamiento antrópico en el conjunto óseo a partir de categorías de alteración térmica (David, 1990), presencia y tipo de huellas de corte 
(Binford, 1981; Nilssen, 2000) y tipo de fractura (Johnson, 1985). Para este último caso se relevó la cantidad de muescas, puntos de impacto y negativos de lascado. También se registraron atributos de evidencias tecnológicas en los especímenes, siguiendo los criterios macroscópicos propuestos por distintos autores (David, 2007; Johnson, 1985; Scheinsohn, 2010; entre otros).

Se evaluó la diversidad del conjunto, entendida como la estructura y composición de la fauna (sensu Lyman, 2008). Se determinó la riqueza taxonómica, por medio del uso del Ntaxa (Grayson, 1991), que considera la suma del número de taxones identificados, teniendo en cuenta los niveles taxonómicos de identificación alcanzados. Dado que esta medida está condicionada por el tamaño de la muestra, se efectuó una curva de rarefacción para evaluar el incremento del Ntaxa en función de la forma de la misma. La curva se obtuvo por medio del programa estadístico PAST version 2.08. Además, se estimó la heterogeneidad a partir de la aplicación del índice de Shannon-Wiener. Este asume que todas las especies están representadas de igual manera en la muestra. También se determinó la dominancia, la cual da mayor peso a las especies dominantes, por lo cual los taxa más raros no afectarían la diversidad (Hammer y Harper, 2006).

Finalmente, de manera complementaria a las medidas de diversidad, se utilizó el Índice de Artiodáctilos (IA) para evaluar la orientación al procuramiento de los mismos en la dieta (Broughton, 1994). El IA fue calculado dividiendo la suma del NISP total de artiodáctilos por la suma de este número y el NISP total de armadillos (exceptuando las placas) y roedores. Se eligieron estos taxones porque representan presas frecuentemente consumidas y jerarquizadas como de alto y bajo rinde económico, respectivamente. Para las medidas de diversidad e IA se consideraron sólo aquellos taxones que presentaban evidencias de explotación antrópica.

\section{Resultados}

\section{Análisis de las variables tafonómicas}

Las variables tafonómicas fueron relevadas sobre 563 especímenes (Tabla 1). La mayoría de los restos se encuentra en el estadío 0 de meteorización en tanto que el $20 \%$ se distribuye principalmente entre los estadíos 1 y 2 . Por otro lado, en el 33\% de los especímenes se relevaron manchas de manganeso que en su mayoría cubrían menos de la mitad de su superficie. Por otra parte, en más de la mitad de la muestra se identificó abrasión sedimentaria, aunque predominantemente en el estadío 1. La acción de roedores y raíces se presentó con porcentajes importantes en la superficie cortical de los elementos (Tabla 1). Ambas variables pudieron haber obliterado las huellas antrópicas.

Un porcentaje significativo de la muestra presentaba fracturas. Se consignó si estas eran modernas o antiguas y en este último caso se intentó identificar aquellas de origen antrópico. La mayor parte de las fracturas fue asignada a la categoría "antigua" (ca. $82 \%$ ), que se prefirió por sobre la de "postdepositacional", debido a que no resultó posible distinguir para los huesos con tejido trabecular si se realizaron en estado fresco o seco debido a la falta de criterios diagnósticos. En una importante cantidad de restos se registró la presencia de tinción oscura sobre la superficie cortical de los restos, pudiendo distinguirse del manganeso. Esta variable puede haber generado la imposibilidad de reconocer la alteración térmica en el estadío carbonizado, que se caracteriza por la presencia de color negro. En cuanto a las marcas de carnívoros y pisoteo, las mismas fueron muy escasas.

Finalmente, para el caso de los procesos afectados por la densidad mineral, se consideró la proporción entre las epífisis proximal y distal de la tibia y el húmero de guanaco. En ambos casos los valores son idénticos (33,33\% y $16,15 \%$, respectivamente). 


\begin{tabular}{|c|c|c|c|c|c|}
\hline \multicolumn{2}{|l|}{ Variable } & \multirow{2}{*}{$\begin{array}{c}\begin{array}{c}\text { NISP por } \\
\text { categoría }\end{array} \\
438 \\
\end{array}$} & \multirow{2}{*}{$\begin{array}{c}\text { NISP\% por } \\
\text { categoría } \\
77,8 \\
\end{array}$} & \multirow{2}{*}{$\begin{array}{c}\text { NISP total } \\
438 \\
\end{array}$} & \multirow{2}{*}{$\begin{array}{c}\text { NISP\% total } \\
77,8 \\
\end{array}$} \\
\hline & Estadío o & & & & \\
\hline Meteorización & $\begin{array}{l}\text { Estadío } 1 \\
\text { Estadío } 2 \\
\text { Estadío } 3 \\
\text { Estadío } 4 \\
\text { Estadío } 5\end{array}$ & $\begin{array}{l}52 \\
62 \\
10 \\
1 \\
- \\
\end{array}$ & $\begin{array}{c}9,24 \\
11,01 \\
1,78 \\
0,18 \\
- \\
\end{array}$ & 125 & 22,21 \\
\hline & Ausencia & 378 & 67,14 & 378 & 67,14 \\
\hline Manganeso & $\begin{array}{l}0-25 \% \\
26-50 \% \\
51-75 \% \\
76-100 \% \\
\end{array}$ & $\begin{array}{l}87 \\
79 \\
15 \\
4 \\
\end{array}$ & $\begin{array}{c}15,45 \\
14,03 \\
2,66 \\
0,71 \\
\end{array}$ & 185 & 32,86 \\
\hline & Estadío o & 260 & 46,18 & 260 & 46,18 \\
\hline Abrasión sedimentaria & $\begin{array}{l}\text { Estadío } 1 \\
\text { Estadío } 2 \\
\text { Estadío } 3\end{array}$ & $\begin{array}{c}205 \\
94 \\
4 \\
\end{array}$ & $\begin{array}{c}36,41 \\
16,7 \\
0,71\end{array}$ & 303 & 53,82 \\
\hline & Ausencia & 382 & 67,85 & 382 & 67,85 \\
\hline Marcas de raíz & $\begin{array}{l}0-25 \% \\
26-50 \% \\
51-75 \% \\
75-100 \%\end{array}$ & $\begin{array}{c}132 \\
33 \\
8 \\
8 \\
\end{array}$ & $\begin{array}{l}23,45 \\
5,86 \\
1,42 \\
1,42 \\
\end{array}$ & 181 & 32,15 \\
\hline Marcas de carnívoro & $\begin{array}{l}\text { Ausencia } \\
\text { Presencia }\end{array}$ & $\begin{array}{c}557 \\
6 \\
\end{array}$ & $\begin{array}{c}98,93 \\
1,07 \\
\end{array}$ & $\begin{array}{c}557 \\
6 \\
\end{array}$ & $\begin{array}{c}98,93 \\
1,07 \\
\end{array}$ \\
\hline & Ausencia & 427 & 75,84 & 427 & 75,84 \\
\hline Marcas de roedor & $\begin{array}{l}0-25 \% \\
26-50 \% \\
51-75 \% \\
76-100 \% \\
\end{array}$ & $\begin{array}{c}105 \\
29 \\
2 \\
-\end{array}$ & $\begin{array}{c}18,65 \\
5,15 \\
0,36 \\
- \\
\end{array}$ & 136 & 24,16 \\
\hline Pisoteo & $\begin{array}{l}\text { Ausencia } \\
\text { Presencia }\end{array}$ & $\begin{array}{c}552 \\
11 \\
\end{array}$ & $\begin{array}{c}98,05 \\
1,95\end{array}$ & $\begin{array}{c}552 \\
11 \\
\end{array}$ & $\begin{array}{c}98,05 \\
1,95 \\
\end{array}$ \\
\hline Fractura & $\begin{array}{l}\text { Ausencia } \\
\text { Presencia }\end{array}$ & $\begin{array}{l}152 \\
411 \\
\end{array}$ & $\begin{array}{l}27 \\
73 \\
\end{array}$ & $\begin{array}{r}152 \\
411 \\
\end{array}$ & $\begin{array}{l}27 \\
73 \\
\end{array}$ \\
\hline Tinción oscura & $\begin{array}{l}\text { Ausencia } \\
\text { Presencia } \\
\end{array}$ & $\begin{array}{l}132 \\
431 \\
\end{array}$ & $\begin{array}{l}23,45 \\
76,55 \\
\end{array}$ & $\begin{array}{r}132 \\
431 \\
\end{array}$ & $\begin{array}{l}23,45 \\
76,55 \\
\end{array}$ \\
\hline
\end{tabular}

Tabla 1. Análisis de las variables tafonómicas sobre los especímenes óseos.

\section{Representación taxonómica}

En la Tabla 2 se presentan los resultados de la estructura taxonómica del sitio (NSP = 2.583). En líneas generales, se observa el predominio de las placas óseas de armadillo y de las cáscaras de huevo. Sin embargo, teniendo en cuenta el resto de los elementos, se determinó la presencia de 10 taxones, de los cuales nueve presentan evidencias de procesamiento antrópico. La excepción es la mara, para la cual se identificó solo un molar. En cuanto a la frecuencia de los especímenes, predomina el guanaco, seguido por los armadillos, la vizcacha, el venado de las pampas y en bajas frecuencias, las aves y los carnívoros. A continuación, se describe la representación esqueletaria para los taxones relevados. 


\begin{tabular}{|c|c|c|c|c|c|c|c|c|}
\hline Clase & Orden & Familia & Género & Especie & MNI & NISP & NISP\% & $\mathbf{P}$ \\
\hline Mammalia(g) & Artiodactyla & & & $\begin{array}{l}\text { Lama guanicoe } \\
\text { Ozotoceros bezoarticus }\end{array}$ & $\begin{array}{l}\text { NA } \\
\text { NA } \\
4 \\
2\end{array}$ & $\begin{array}{c}14 \\
11 \\
228 \\
23\end{array}$ & $\begin{array}{l}\text { NA } \\
\text { NA } \\
50,56 \\
5,09\end{array}$ & $\begin{array}{l}\text { NA } \\
\text { NA } \\
x \\
X\end{array}$ \\
\hline $\operatorname{Mammalia}(\mathrm{m})$ & 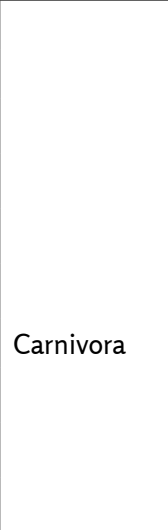 & Dasypodidae & Lycalopex & $\begin{array}{l}\text { Chaetophractus villosus } \\
\text { Zaedyus pichiy } \\
\text { Dolichotis patagonum } \\
\text { Lagostomus maximus } \\
\text { Lycalopex gymnocercus } \\
\text { Conepatus chinga }\end{array}$ & $\begin{array}{c}\text { NA } \\
\text { NA } \\
3 \\
1 \\
1 \\
2 \\
\text { NA } \\
\text { NA } \\
1 \\
1\end{array}$ & $\begin{array}{l}68 \\
81 \\
43 \\
3 \\
1 \\
29 \\
3 \\
4 \\
4 \\
4\end{array}$ & $\begin{array}{l}\text { NA } \\
28,16 \\
0,22 \\
6,43 \\
\text { NA } \\
1,77 \\
0,89\end{array}$ & $\begin{array}{l}\text { NA } \\
X \\
X \\
X \\
\text { NA } \\
\text { NA } \\
X \\
X\end{array}$ \\
\hline Aves & & Tinamidae & & Rhea americana & $\begin{array}{c}\text { NA } \\
5 \\
2\end{array}$ & $\begin{array}{l}16 \\
16 \\
15\end{array}$ & $\begin{array}{l}\mathrm{NA} \\
3,55 \\
3,33\end{array}$ & $\begin{array}{l}\text { NA } \\
X \\
X\end{array}$ \\
\hline Subtotal & & & & & & 563 & 100 & \\
\hline & & $\begin{array}{l}\text { Rheidae(h) } \\
\text { Dasypodidae* }\end{array}$ & & $\begin{array}{l}\text { Chaetophractus villosus* } \\
\text { Zaedyus pichiy* }\end{array}$ & $\begin{array}{l}\text { NA } \\
\text { NA } \\
\text { NA } \\
\text { NA }\end{array}$ & $\begin{array}{l}328 \\
879 \\
482 \\
331\end{array}$ & & $\begin{array}{l}\text { NA } \\
\text { NA } \\
\text { NA } \\
\text { NA }\end{array}$ \\
\hline \multicolumn{5}{|l|}{ Total } & & 2583 & & \\
\hline
\end{tabular}

Tabla 2. Representación taxonómica del conjunto de Laguna de los Pampas.

\section{Guanaco}

Se construyó el perfil de partes esqueletarias de guanaco, a partir del cual pudieron recomponerse 112 elementos (Tabla 3; Figura 2). La hemipelvis dio cuenta de un número mínimo de cuatro individuos, tres de los cuales son adultos y uno neonato. Si bien los restos dentarios estaban muy fragmentados, la presencia de un incisivo deciduo permitió determinar a un individuo de nueve meses de gestación a 15 días de edad. Por otro lado, a partir de un tercer molar permanente se pudo identificar a un guanaco de 48 a 84 meses.

Los valores más altos de MAU\% fueron obtenidos para el radiocúbito proximal y la hemipelvis, seguidos por la diáfisis de la tibia, el cráneo, la diáfisis del húmero y del radiocúbito, el fémur, la rótula, el calcáneo y el astrágalo. Con valores menores al $50 \%$ se ubicaron el sacro, la hemimandíbula, las vértebras lumbares y cervicales, la escápula, la primera falange, los huesos del carpo, el metacarpo proximal y distal y la tibia proximal y distal. Los valores más bajos se registraron para la segunda y tercera falange, las vértebras torácicas y caudales, los huesos del tarso, el húmero proximal y distal, las costillas y la diáfisis del metatarso. Finalmente, las esternebras, la diáfisis del metacarpo, el axis y el radiocúbito distal están ausentes. Los valores de MAU\% fueron correlacionados con el índice de Utilidad de Carne modificado (positiva y no significativa, Rs $=0,314, p=0,09$ ) y con el Índice de Médula (positiva y no significativa, Rs $=0,550, p=0,272$ ). 


\begin{tabular}{|c|c|c|c|c|c|c|c|c|c|c|c|c|c|c|c|}
\hline \multirow{2}{*}{ Unidad anatómica } & \multicolumn{4}{|c|}{ No Fusionado } & \multicolumn{4}{|c|}{ Fusionado } & \multicolumn{3}{|c|}{ No determina } & \multicolumn{4}{|c|}{ Medidas } \\
\hline & Izq & Der & $\mathrm{Ax}$ & Indt & Izq & Der & $\mathrm{Ax}$ & Indt & Izq & Der & Indt & MNI & MNE & MAU & MAU \% \\
\hline Cráneo & & & 1 & & & & 1 & & & & & 2 & 2 & 2 & 66,66 \\
\hline Hemimandíbula & & & & & & & 1 & & & & & 1 & 1 & 1 & 33,33 \\
\hline V. Atlas & & & & & & & & & & & 1 & 1 & 1 & 1 & 33,33 \\
\hline V. Axis & & & & & & & & & & & & o & o & o & o \\
\hline V. Cervical & & & 1 & & & & 3 & & & & & 2 & 4 & 0,8 & 26,66 \\
\hline V. Torácica & & & 1 & & & & 5 & & & & & 2 & 6 & 0,5 & 16,66 \\
\hline V. Lumbar & & & 1 & & & & 5 & & & & 1 & 2 & 7 & 1 & 33,33 \\
\hline V. Caudal & & & & & & & 1 & & & & & 1 & 1 & 0,07 & 2,33 \\
\hline Esternebra & & & & & & & & & & & & o & o & o & o \\
\hline Sacro & & & & & & & 1 & & & & & 1 & 1 & 1 & 33,33 \\
\hline Costilla & 1 & & & & 1 & 1 & & 2 & 2 & 1 & & 2 & 8 & 0,33 & 11 \\
\hline Escápula & & & & & 1 & 1 & & & & & & 1 & 2 & 1 & 33,33 \\
\hline Húmero Px & & & & & & 1 & & & & & & 1 & 1 & 0,5 & 16,66 \\
\hline Húmero D & 1 & & & & & & & & 2 & 1 & & 3 & 4 & 2 & 66,66 \\
\hline Húmero Dt & & & & & 1 & & & & & & & 1 & 1 & 0,5 & 16,66 \\
\hline Radiocúbito Px & & & & 1 & 3 & 2 & & & & & & 4 & 6 & 3 & 100 \\
\hline Radiocúbito D & 1 & & & & & 2 & & & & & 1 & 3 & 4 & 2 & 66,66 \\
\hline Radiocúbito Dt & & & & & & & & & & & & o & o & o & o \\
\hline Escafoides & & & & & & & & & 1 & 2 & & 2 & 3 & 1,5 & 50 \\
\hline Mágnum & & & & & & & & & & 2 & & 2 & 2 & 1 & 33,33 \\
\hline Pisciforme & & & & & & & & & & & & o & o & o & o \\
\hline Lunar & & & & & & & & & 1 & 2 & & 2 & 3 & 1,5 & 50 \\
\hline Trapezoide & & & & & & & & & & & & o & o & o & o \\
\hline Uncifrome & & & & & & & & & & & & o & o & o & o \\
\hline Cuneiforme & & & & & & & & & 2 & 3 & & 3 & 5 & 2,5 & 83,33 \\
\hline Metacarpo Px & & & & & & & & & 1 & 1 & & 1 & 2 & 1 & 33,33 \\
\hline Metacarpo diaf & & & & & & & & & & & & o & o & o & o \\
\hline Hemipelvis & 1 & & & & 2 & 3 & & & & & & 4 & 6 & 3 & 100 \\
\hline Fémur Px & & & & & 1 & 2 & & & & & 1 & 2 & 4 & 2 & 66,66 \\
\hline Fémur D & & & & & & & & & 1 & 1 & 1 & 2 & 3 & 1,5 & 50 \\
\hline Fémur Dt & & & & & 3 & 1 & & & & & & 3 & 4 & 2 & 66,66 \\
\hline Rótula & & & & & & & & & & 1 & 3 & 2 & 4 & 2 & 66,66 \\
\hline Tibia Px & & & & & 2 & & & & & & & 2 & 2 & 1 & 33,33 \\
\hline Tibia D & 1 & 1 & & & 2 & & & & & 1 & & 3 & 5 & 2,5 & 83,33 \\
\hline Tibia Dt & 1 & & & & 1 & & & & & & & 2 & 2 & 1 & 33,33 \\
\hline Calcáneo & 1 & & & & 1 & 1 & & & & 1 & & 2 & 4 & 2 & 66,66 \\
\hline Astrágalo & & & & & & & & & 3 & 1 & & 3 & 4 & 2 & 66,66 \\
\hline $1^{\circ} \operatorname{tarsiano}$ & & & & & & & & & & & 1 & 1 & 1 & 0,5 & 16,66 \\
\hline Cuboides & & & & & & & & & 1 & & & 1 & 1 & 0,5 & 16,66 \\
\hline Fibular & & & & & & & & & 1 & & & 1 & 1 & 0,5 & 16,66 \\
\hline Navicular & & & & & & & & & & & & o & $\mathrm{o}$ & o & o \\
\hline Ectocuneiforme & & & & & & & & & & & & o & o & o & o \\
\hline Sesamoide & & & & & & & & & 5 & & & 1 & 5 & 0,31 & 10,33 \\
\hline Metatarso Px & & & & & & & & & & & & o & o & o & o \\
\hline Metatarso D & & & & & & & & & & & 1 & 1 & 1 & 0,5 & 16,66 \\
\hline Metapodio D & & & & 1 & & & & & & & 3 & 2 & 4 & 0,5 & 16,66 \\
\hline Metapodio Ds & & & & 2 & & & & 4 & & & & 2 & 6 & 1,5 & 50 \\
\hline $1^{\circ}$ falange & & & & 2 & & & & 6 & & & & 2 & 8 & 1 & 33,33 \\
\hline $2^{\circ}$ falange & & & & & & & & 2 & & & & 1 & 2 & 0,25 & 8,33 \\
\hline $3^{\circ}$ falange & & & & & & & & & & & 2 & 1 & 2 & 0,25 & 8,33 \\
\hline
\end{tabular}

Tabla 3. Perfil de partes esqueletarias de guanaco para el sitio Laguna de los Pampas. 


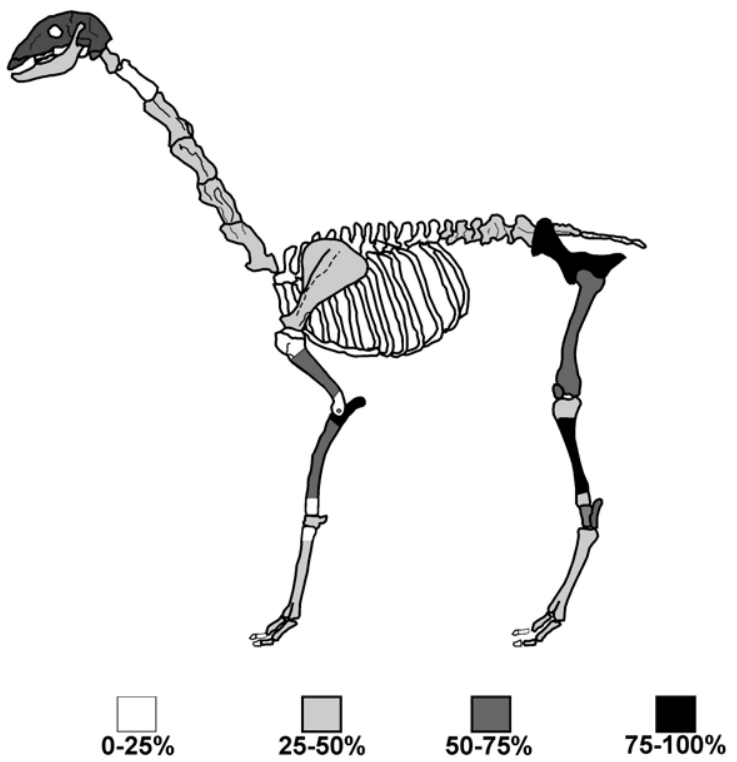

Figura 2. Representación gráfica del perfil de partes esqueletarias de guanaco del sitio Laguna de los Pampas.

Se evaluó la intensidad y extensión de la fragmentación de los restos de guanaco a partir de las medidas de NISP: MNE y Completitud \% (Tabla 4). Los resultados de estos análisis muestran que las diáfisis de los huesos largos presentan menor porcentaje de completitud y mayor extensión de la fragmentación.

\section{Venado de las pampas}

Se determinó un NISP de 23 y un número mínimo de dos individuos adultos de venado de las pampas. El MNI fue estimado sobre la base del metacarpo, aunque la mayoría de los elementos corresponden a un solo animal. Las principales unidades identificadas son las extremidades (radio, fémur, metapodios, húmero, algunas falanges y huesos articulares). El esqueleto axial está representado por una hemipelvis y una vértebra lumbar.

\section{Armadillos}

En el caso de los armadillos, se determinaron dos especies (Ch. villosus y Z. pichiy) esperables en el sitio de acuerdo con las características ambientales del área. La mayor cantidad de elementos postcraneales fue asignada a la categoría de Dasypodidae y corresponde a vértebras caudales, falanges y metapodios, para los cuales se dificultó su asignación específica. Estas unidades anatómicas se complementan con los huesos largos determinados como peludo. En cuanto al piche, se identificaron sólo unos pocos elementos diagnósticos. Si se considera a los armadillos como un conjunto, no hay un predominio de ciertas partes por sobre otras.

Con respecto a las placas óseas (ver Tabla 2), se identificaron 14 osteodermos de peludo $(2,9 \%)$ y tres de piche $(0,91 \%)$ con alteración térmica (calcinación en todos los especímenes). En el caso de la categoría Dasypodidae, ocho de las placas presentaban 


\begin{tabular}{|c|c|c|}
\hline Unidad anatómica & Completitud\% & NISP/MNE \\
\hline Cráneo & 9,09 & 5,5 \\
\hline Vértebra cervical & 11,11 & 1,8 \\
\hline Vértebra lumbar & 11,11 & 2,57 \\
\hline Vértebra torácica & 9,09 & 1,83 \\
\hline Vértebra caudal & o & 1 \\
\hline Costilla & 5,55 & 2,57 \\
\hline Escápula & o & 2 \\
\hline Húmero (proximal) & o & 1 \\
\hline Húmero (diáfisis) & o & 3,25 \\
\hline Húmero (distal) & o & 1 \\
\hline Radiocúbito (proximal) & 16,66 & 1 \\
\hline Radiocúbito (diáfisis) & o & 1,75 \\
\hline Metacarpo (proximal) & o & 1 \\
\hline Hemipelvis & o & 1,5 \\
\hline Sacro & o & 1 \\
\hline Fémur (proximal) & o & 1 \\
\hline Fémur (diáfisis) & o & 3,33 \\
\hline Fémur (distal) & o & 1,75 \\
\hline Tibia (proximal) & o & 1 \\
\hline Tibia (diáfisis) & o & 2 \\
\hline Tibia (distal) & 50 & 1 \\
\hline Calcáneo & o & 1,25 \\
\hline Metatarso (diáfisis) & o & 1 \\
\hline Metapodio (diáfisis) & o & 1,75 \\
\hline Metapodio (distal) & 27,27 & 1,83 \\
\hline $1^{\circ}$ falange & 6,25 & 2 \\
\hline $2^{\circ}$ falange & o & 2,5 \\
\hline $3^{\circ}$ falange & o & 1 \\
\hline
\end{tabular}

Tabla 4. Completitud\% y extensión de la fragmentación para los elementos de guanaco.

calcinación $(0,91 \%)$ y una carbonización $(0,11 \%)$. En todos los taxones la alteración térmica se presenta en ambas caras. En relación con la distribución de las placas, las mismas se encontraban entre los 0,74 y los 2 metros de profundidad y su frecuencia por nivel de excavación resultó similar a lo largo de toda la secuencia.

\section{Roedores}

En el conjunto están presentes dos especies de roedores asignables a la categoría de pequeños mamíferos ( $1 \mathrm{a} 15 \mathrm{~kg}$ ). Uno de ellos es la mara, identificado a partir de un molar. Por el momento, este escaso registro no permite arriesgar hipótesis acerca de su origen en el sitio. En cuanto a la vizcacha, se determinó un número mínimo de dos individuos, a partir del húmero, aunque la mayoría de los especímenes corresponde a un solo animal. Están presentes casi todos los elementos, aunque es notable la ausencia de costillas y vértebras torácicas y cervicales. 


\section{Carnívoros}

En LLP están representadas al menos dos especies de carnívoros, ambas con evidencias de procesamiento: zorro pampeano y zorrino. Para esta última se registraron dos vértebras, la hemipelvis y el cúbito $(\mathrm{MNI}=1)$, en tanto que para el zorro se determinaron dos vértebras, un fragmento del cráneo y el húmero. Otras dos vértebras, un premolar y una falange fueron clasificadas a nivel de género (Lycalopex).

\section{Ñandú}

Se identificaron 15 especímenes de ñandú que, sobre la base del tarso-metatarso, dan cuenta de un número mínimo de dos individuos. Se recuperaron principalmente huesos largos, entre los cuales se encuentran el tibio-tarso, el tarso-metatarso y el fémur. Otros elementos representados son dos vértebras y una tercera falange. Para la Familia Rheidae también se determinaron 328 fragmentos de cáscara de huevo, 11 de los cuales presentaban alteración térmica.

\section{Aves pequeñas}

Se consideró dentro de este conjunto a 32 especímenes correspondientes a aves de menos de $1 \mathrm{~kg}$ de peso. Si bien estos materiales se analizarán en detalle en el futuro, por el momento puede mencionarse que 16 de ellos pudieron ser determinados como Aves y 16 como Tinamidae. Para esta última categoría taxonómica pudo estimarse la presencia de al menos cinco individuos, sobre la base del hueso coracoides. Entre estos se incluyen elementos del tamaño de las especies Nothura maculosa y Eudromia rynchotus.

\section{Procesamiento antrópico}

Se identificaron 57 especímenes (10,12\%) con huellas de corte. De estas, ocho $(14,03 \%)$ fueron asignadas a cuereo, $19(33,33 \%)$ a fileteo, $14(24,56 \%)$ a desarticulación y 16 $(28,07 \%)$ resultaron indeterminadas. Si bien la mayoría de las huellas se registraron en el guanaco, también se destaca la presencia en otros taxones, predominando el fileteo y la desarticulación. En la Figura 3 se presenta un ejemplo de las huellas de corte relevadas en un coracoides de Tinamidae. Por otro lado, setenta y dos (17,76\%) especímenes presentaban fractura antrópica, 36 (6,42\%) alteración térmica y tres $(0,53 \%)$ rasgos tecnológicos. En la Tabla 5 se presentan los datos obtenidos para cada taxón (se exceptúan los indeterminados). Allí se observa la alta frecuencia de fracturas antrópicas en los huesos largos para los artiodáctilos y el ñandú (consideradas sobre el total de huesos fracturados).

Además de las evidencias mencionadas, se identificaron tres especímenes de guanaco con rasgos tecnológicos, los cuales son descriptos por Messineo y coautores (2017). Se trata de un desecho de manufactura, un instrumento en bisel (ambos sobre tibias) y un instrumento sobre un radiocúbito que presenta muescas y puntos de impacto en su extremo activo.

\section{Diversidad taxonómica e índice de artiodáctilos}

En relación con las medidas diversidad taxonómica, el Ntaxa dio un resultado de nueve. Este incluye a los siguientes taxones: guanaco, venado de las pampas, peludo, piche, vizcacha, zorro pampeano, zorrino, tinámido y ñandú. En relación con la curva de rarefacción, la misma alcanza rápidamente una forma asintótica, lo cual implica que se requirieron pocas muestras para acumular a todas las especies (Figura 4). 


\begin{tabular}{|c|c|c|c|c|c|c|c|c|c|c|c|c|c|c|c|c|c|c|}
\hline \multirow{2}{*}{ Taxón } & \multicolumn{2}{|c|}{ HCT } & \multicolumn{2}{|c|}{ Fil } & \multicolumn{2}{|c|}{ Des } & \multicolumn{2}{|c|}{ Cuer } & \multicolumn{2}{|c|}{ Ind } & \multicolumn{2}{|c|}{ ATT } & \multicolumn{2}{|c|}{ Carb } & \multicolumn{2}{|c|}{ Cal } & \multicolumn{2}{|c|}{ F. Ant } \\
\hline & $\mathrm{N}$ & $\%$ & $\mathrm{~N}$ & $\%$ & $N$ & $\%$ & $\mathrm{~N}$ & $\%$ & $\mathbf{N}$ & $\%$ & $\mathbf{N}$ & $\%$ & $\mathbf{N}$ & $\%$ & $\mathbf{N}$ & $\%$ & $\mathbf{N}$ & $\%$ \\
\hline Lama guanicoe & 39 & 17,10 & 14 & 35,9 & 10 & 25,64 & 7 & 17,95 & 8 & 20,51 & 16 & 7,02 & 8 & 50 & 8 & 50 & 48 & 24,61 \\
\hline $\begin{array}{l}\text { Ozotoceros } \\
\text { bezoarticus }\end{array}$ & 2 & 8,69 & 2 & 100 & - & - & - & - & - & - & 3 & 13,04 & 1 & 33,33 & 2 & 66,67 & 5 & 26,32 \\
\hline $\begin{array}{l}\text { Chaetophractus } \\
\text { villosus }\end{array}$ & 2 & 4,65 & 1 & 50 & - & - & - & - & 1 & 50 & 1 & 2,32 & 1 & 100 & - & - & - & - \\
\hline Zaedyus pichiy & 2 & 66,67 & 1 & 50 & 1 & 50 & - & - & - & - & - & - & - & - & - & - & - & - \\
\hline $\begin{array}{l}\text { Lagostomus } \\
\text { maximus }\end{array}$ & 1 & 3,45 & - & - & - & - & 1 & 100 & - & - & 3 & 10,34 & 1 & 33,33 & 2 & 66,67 & 1 & 3,45 \\
\hline Lycalopex & 2 & 25 & 1 & 50 & - & - & - & - & 1 & 50 & 1 & 12,5 & 1 & 100 & - & - & - & - \\
\hline $\begin{array}{l}\text { Conepatus } \\
\text { chinga }\end{array}$ & 1 & 25 & - & - & - & - & - & - & 1 & 100 & - & - & - & - & - & - & - & - \\
\hline Tinamidae & 1 & 6,25 & - & - & 1 & 100 & - & - & - & - & - & - & - & - & - & - & - & - \\
\hline Rhea americana & 3 & 20 & - & - & - & - & - & - & 3 & 100 & - & - & - & - & - & - & 10 & 66,67 \\
\hline
\end{tabular}

Tabla 5. Evidencias de procesamiento para los taxones identificados en Laguna de los Pampas.

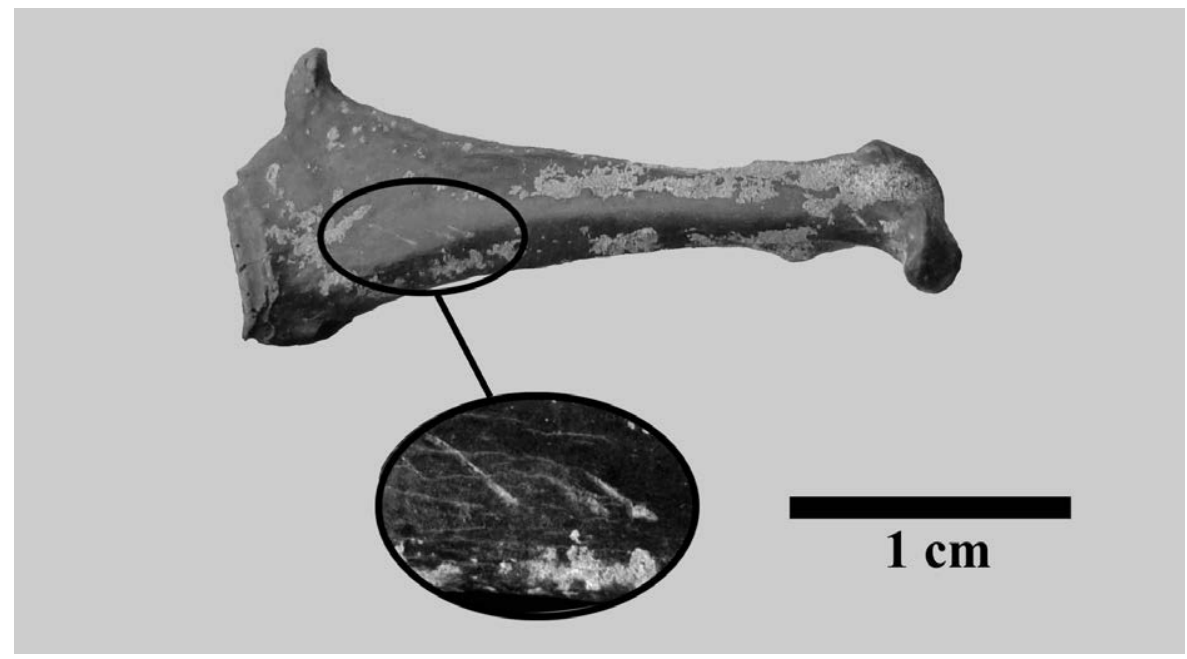

Figura 3. Coracoides de Tinamidae (tamaño Nothura maculosa) con huellas de corte.

El cálculo de la heterogeneidad considerando los taxones explotados en el sitio dio un valor de 1,33. En este caso se excluyeron los restos de Dasypodidae, dado que esta categoría taxonómica se superponía con la de las especies peludo y piche. En cuanto a la dominancia, la misma arrojó un resultado de 0,42 . Considerando que un valor de cero corresponde a que todos los taxa están igualmente presentes y un valor de uno a que una especie domina completamente, este valor es intermedio. Si bien ambos índices estarían condicionados por el tamaño de la muestra, es importante destacar que la dominancia es menos dependiente de esta variable que la heterogeneidad (Magurran, 1988). Teniendo en cuenta que la especie mejor representada es el guanaco, al igual que en la mayoría de los sitios de la región, se aplicó el IA. Dicho índice dio un resultado de 0,62 (artiodáctilos $=251$; armadillos + roedores $=156$ ). Esto indica que la dieta está orientada a este ungulado, si bien el valor es más bajo que en los casos de estrategias de especialización. 


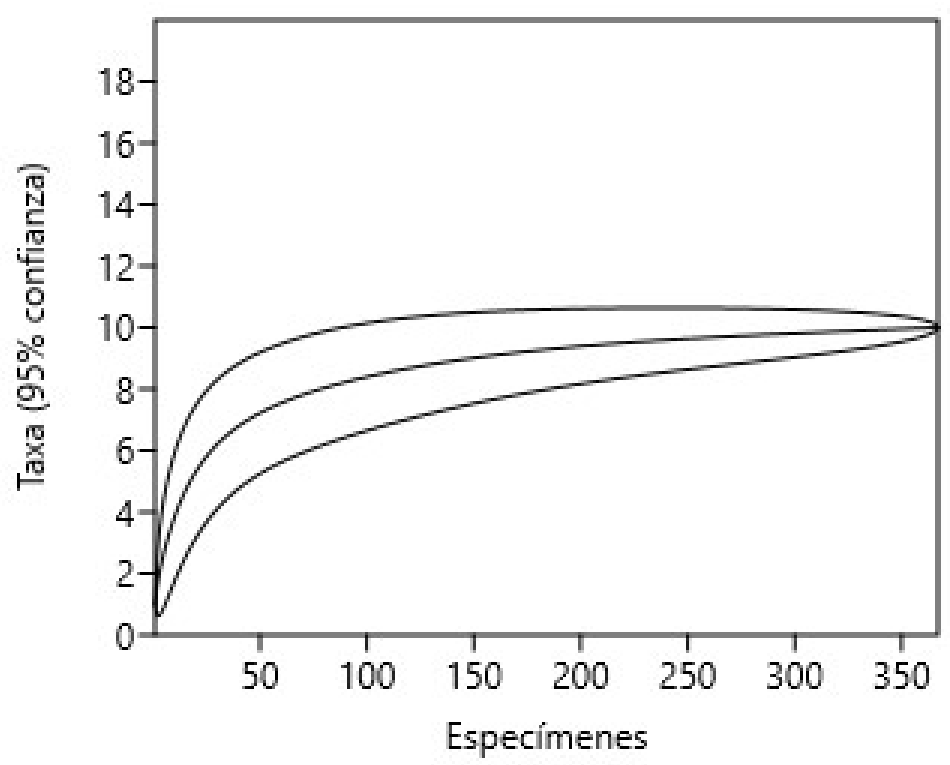

Figura 4. Curva de rarefacción para el sitio Laguna de los Pampas.

\section{Discusión y conclusiones}

Los análisis del conjunto arqueofaunístico de LLP permiten realizar una serie de inferencias acerca de la subsistencia en el área Oeste durante el Holoceno medio. Sin embargo, previamente es necesario considerar algunos aspectos tafonómicos de la muestra. En primer lugar, el perfil de partes esqueletarias de guanaco no alerta acerca de una preservación diferencial de los elementos. En cuanto a los perfiles de meteorización se observa que, si bien existe un porcentaje de especímenes afectados, en la gran mayoría no se registra esta variable. En forma moderada a alta el conjunto está afectado por la presencia de manganeso y abrasión sedimentaria. Ambas variables se vinculan con la presencia de agua, que podría haber circulado entre los sedimentos (Fernández-Jalvo y Andrews, 2003; López González, Grandal-d Ánglade y VidalRomaní, 2006). Sin embargo, estas modificaciones no se registran en forma intensa, con lo cual sería improbable la redepositación de una cantidad significativa de elementos óseos por acción fluvial.

En forma moderada se registró la presencia de marcas de roedores y raíces. Ambos agentes pueden haber contribuido a la mezcla de los restos en el conjunto. En relación con este aspecto, para LLP se cuenta con dos fechados radiocarbónicos con una diferencia de 1200 años. Sin embargo, por el momento no pudieron identificarse criterios que permitan diferenciar componentes en la secuencia, por ejemplo, la presencia diferencial de especies o artefactos característicos. Es probable que esto esté vinculado con la mezcla producida por los agentes mencionados. Es por este motivo que el conjunto de LLP se tomó como una unidad al momento de realizar inferencias sobre el comportamiento humano. Sin embargo, no se desconoce que las tendencias que se mencionan a continuación están promediando diferentes eventos, lo cual puede incidir en algunos de los resultados alcanzados, como el aumento de los valores de diversidad. No obstante, casi ninguno de los contextos de la región pampeana está exento de una baja resolución o la mezcla de materiales (e.g., Gutiérrez, 2006). Se espera que en trabajos futuros, la ampliación de las excavaciones junto con una mayor cantidad de fechados radiocarbónicos y la presencia de marcadores cronológicos permita llegar a diferenciar componentes o unidades en el sitio. 
En cuanto a las tendencias en el uso de la fauna, se observa un predominio de guanaco y una importante variedad de taxones explotados. La evaluación de las medidas de diversidad, en conjunto con la aplicación del IA, permitió determinar que una importante variabilidad en la dieta, si bien la misma estuvo dominada por el guanaco. Entre los taxones explotados se encuentran, además del camélido mencionado, el venado de las pampas, el peludo, el piche, la vizcacha, el zorro, el zorrino, el ñandú y al menos una de las especies de tinámidos registrada en el sitio. En relación con la explotación de guanaco, los perfiles de partes muestran una gran variedad de unidades en el conjunto y la correlación con los índices de carne y médula no fueron significativas, aunque en el primer caso el resultado fue cercano al límite de significación. Esto, sumado a que se observa, de manera cualitativa, un mayor predominio del esqueleto apendicular por sobre el axial, podría indicar el transporte de algunas de las partes de mayor rinde y médula al sitio. Esta tendencia deberá indagarse en trabajos futuros. Por otra parte, considerando la completitud y extensión de la fragmentación, al igual que en otros sitios del área Interserrana (Álvarez, 2014a), se observa la explotación de la médula pero no de la grasa del tejido trabecular. Para este último caso se hubiera esperado una mayor fragmentación de las epífisis y las vértebras. En cuanto al venado de las pampas y el ñandú, la presencia de una mayor cantidad de elementos del esqueleto apendicular podría indicar el transporte de algunas unidades de estos animales o el descarte del esqueleto axial en otro lugar. Por el contrario, las especies pequeñas habrían sido trasladadas enteras.

Como fue expresado en la introducción, son escasos los análisis sistemáticos de los conjuntos arqueofaunísticos de otros sitios del área Oeste. Sin embargo, existen algunos datos relevantes, como los materiales superficiales provenientes del sitio Laguna Salalé (partido de Florentino Ameghino), correspondientes a los restos óseos de ocho individuos de guanaco, así como especímenes de venado de las pampas y ñandú (Gallego, 2002; Oliva et al., 2004). En el caso de Laguna Arroyo Venado se recuperaron restos de guanaco, venado de las pampas, ñandú, vizcacha, peludo y coipo. Para el camélido se registraron huellas de corte y fracturas antrópicas. Además, debido a la presencia de alfarería, este sitio fue asignado al Holoceno tardío (Oliva et al., 2015). Por otro lado, existen estudios preliminares de un conjunto en estratigrafía del sitio El Doce en el cual se observa el predominio del guanaco y la presencia de una diversidad importante de especies (Cornaglia Fernández, 2014), pero este contexto no cuenta con fechados radiocarbónicos, a diferencia de los materiales superficiales de la misma localidad (Ávila, 2011). Otro sitio recientemente excavado en el área Oeste es Laguna Cabeza de Buey, el cual presenta unidades asignables a distintos bloques temporales. $\mathrm{Si}$ bien la muestra es escasa, se observa un predominio del guanaco para la primera mitad del Holoceno medio ( $c a .6800$ años AP, $\mathrm{N}=12$ ), finales de este período ( $c a .4150$ años AP, $\mathrm{N}=29$ ) y el Holoceno tardío (fechado relativo, $\mathrm{N}=4$ ) (Scheifler y Messineo, 2016). Finalmente, en el partido de Trenque Lauquen si bien el guanaco domina las muestras, este camélido estuvo complementado con otros taxones hacia los $c a .7500$ años AP (zorro, venado de las pampas y un ave rapaz), en tanto que hacia los ca. 3000 años AP se evidencia una mayor especialización sobre este animal en el sitio Huencú Nazar (Scheifler et al., 2017). En resumen, las muestras con las cuales se cuenta hasta el momento permiten proponer un predominio del consumo de guanaco en el área Oeste y algunos datos recientes podrían indicar una mayor diversidad en el Holoceno medio, coincidiendo con los resultados alcanzados para LLP.

Si se consideran los estudios de la subsistencia en el resto de las áreas de la subregión Pampa Húmeda, se observan claras diferencias con algunos sectores. Este es el caso del Norte y la Depresión del Salado, caracterizadas por el aprovechamiento intensivo de peces y de roedores, respectivamente (Acosta, 2005; Escosteguy et al., 2015). Por el contrario, el tipo de registro, la disponibilidad de los recursos y el ambiente de pastizales abiertos muestra mayores similitudes con las áreas Sur, Interserrana y las 


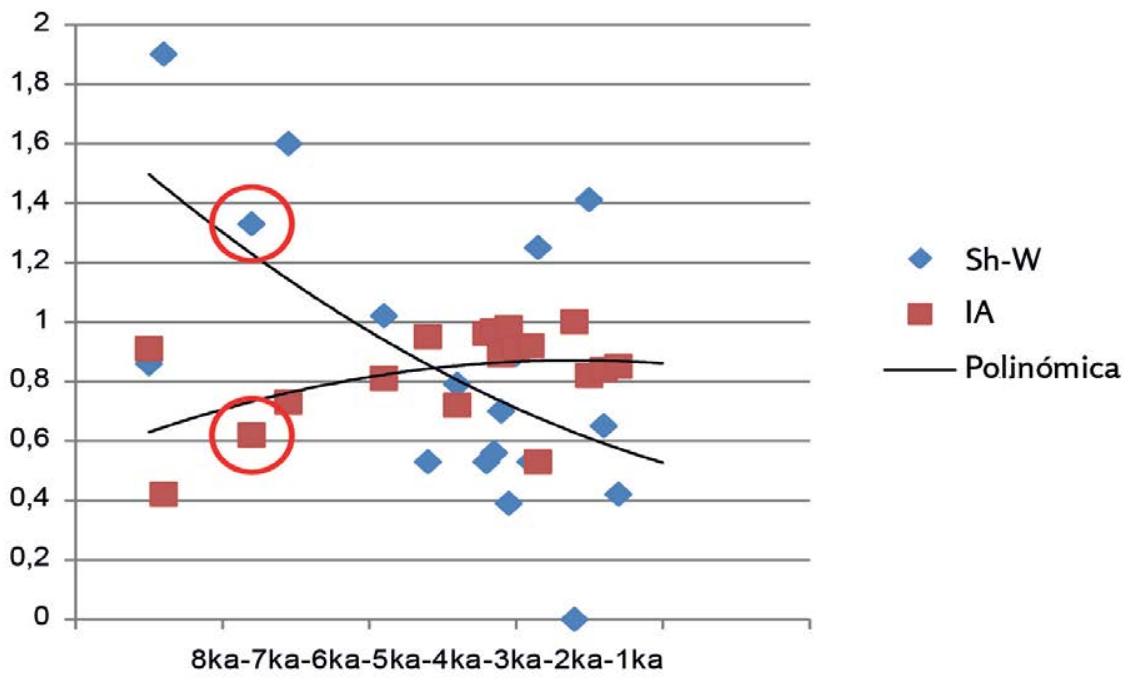

Figura 5. Valores de heterogeneidad e índice de artiodáctilos para el área Interserrana y para Laguna de los Pampas (círculos rojos).

zonas adyacentes a Ventania y Tandilia. En los sitios de estos lugares también se observa un predominio del guanaco, aunque existen variaciones locales a lo largo de Holoceno debido a los cambios sociales, tecnológicos y ambientales. Considerando los datos disponibles, se decidió comparar los resultados de LLP con aquellos de heterogeneidad e IA obtenidos para el sudeste de la Región Pampeana, que corresponden principalmente a conjuntos de áreas abiertas del área Interserrana, aunque algunos de ellos también podrían ubicarse en las áreas Sur o Ventania (e.g., Paso Vanoli en Frontini, 2012). Las referencias de las muestras utilizadas y los valores para cada una de ellas están disponibles en Álvarez (2014a). Si bien los datos recabados para LLP sólo representan a un período acotado (ca. 5800 a 7000 años AP), en ambas áreas (Interserrana y Oeste) se observa para este momento del Holoceno medio una dieta orientada hacia el consumo de artiodáctilos que se complementa con otros taxones, como el ñandú y especies de menor tamaño. En la Figura 5 se observan, marcados con círculos rojos, los valores de LLP, que indican una dieta diversa y con predominio del guanaco, pero no una alta especialización, como sí se registra desde la segunda mitad del Holoceno medio.

Para finalizar, la comparación realizada permite proponer que el área Oeste parece seguir un patrón similar al registrado para el área Interserrana. En este sentido, se observa para el Holoceno medio una dieta basada en el consumo de guanaco pero complementada con una amplia variedad de taxones. Este estudio constituye un aporte a los recientes estudios de la subsistencia de los cazadores-recolectores que ocuparon las lagunas del área Oeste de la región pampeana. En este sentido, se espera que la continuidad de las investigaciones en este lugar permita contar con una cantidad mayor de sitios para poder realizar inferencias sobre patrones en la dieta de los grupos humanos y sus cambios en el tiempo.

\section{Agradecimientos}

A Marcelo Cardillo y Hernán Marani por su ayuda en diversas instancias de los análisis estadísticos y su interpretación. A Paula Escosteguy, por la gestión editorial de este trabajo. A dos evaluadores anónimos, los cuales aportaron valiosas sugerencias para mejorar el contenido de este manuscrito. A las autoridades de Lincoln/Martínez de 
Hoz y los dueños y administradores de los campos de Laguna de los Pampas: Sergio Leguizamón, Juan Rodríguez, Nicolás Giaccone y Luis Musso. A Ramón Coria, quien descubrió el sitio y colabora permanentemente en las tareas de campo. Al Dr. Pablo Messineo, por la lectura crítica y sus valiosos aportes a este manuscrito. Al INCUAPACONICET por el apoyo institucional que permitió llevar a cabo estas investigaciones. Este trabajo fue financiado con los siguientes proyectos: PICT 2014-2070, PIP No 414, National Geographic Grant \#9737 y PICT 2015-0235. 


\section{Referencias citadas}

"Acosta, A. (2005). Zooarqueología de cazadores-recolectores del extremo nororiental de la provincia de Buenos Aires (humedal del río Paraná inferior, Región Pampeana, Argentina). (Tesis Doctoral inédita), Universidad Nacional de La Plata, Argentina.

》Acosta, A., Loponte, D. y Mucciolo, L. (2010). Comparando estrategias de explotación faunística en el humedal del Paraná inferior: cazadores-recolectores vs. horticultores amazónicos. En M. Gutiérrez, M. De Nigris, P. Fernández, M. Giardina, A. Gil, A. Izeta, G. Neme y H. Yacobaccio (Eds.), Zooarqueología a Principios del Siglo XXI. Aportes Teóricos, Metodológicos y Casos de Estudio (pp. 177-188). Ayacucho: Libros del Espinillo.

»Acosta, A., Loponte, D. y Mucciolo, L. (2014). Variabilidad en la explotación y procesamiento de ungulados en el sector centro-oriental de la región pampeana. Comechingonia, 18(1), 9-32.

» Álvarez, M. C. (2014a). Subsistence patterns during the Holocene in the Interserrana area (pampean region, Argentina): evaluating intensification in resource exploitation. Journal of Anthropological Archaeology, 34, 54-65.

"Álvarez, M. C. (2014b). Tecnología ósea en el Oeste de la región pampeana: identificación de las técnicas de manufactura a partir de evidencias arqueológicas y experimentales. Chungara, Revista de Antropología Chilena, 46(2), 193-210.

"Ávila, J. D. (2011). Resultados de los fechados radiocarbónicos del sitio Laguna El Doce, departamento General López, provincia de Santa Fe. Relaciones de la Sociedad Argentina de Antropología, XXXVI, 337-343.

» Bayón, C., Frontini, R. y Vecchi, R. (2012). Middle Holocene settlements on coastal dunes, southwest Buenos Aires Province, Argentina. Quaternary International, 256, 54-61.

" Behrensmeyer, A. (1978). Taphonomic and ecologic information from bone weathering. Paleobiology, 4, 150-162.

》Binford, L. (1978). Nunamiut Ethnoarchaeology. Nueva York: Academic Press.

" Binford, L. (1981). Bones: Ancient Men and Modern Myths. Nueva York: Academic Press.

" Borrero, L. A. (1990). Fuego-Patagonia bone assemblage and the problem of comunal guanaco hunting. En L. Davis y B. Reeves (Eds.), Hunters of the Recent Past (pp. 373-399). Londres: Unwin Hyman.

"Broughton, J. (1994). Late Holocene resource intensification in the Sacramento Valley, California: The vertebrate evidence. Journal of Archaeological Science, 21, 501-514.

"Catella, L. (2014). Movilidad y utilización del ambiente en poblaciones cazadorasrecolectoras del sur de la región pampeana. La cuenca del arroyo Chasicó como caso de estudio. (Tesis Doctoral inédita), Universidad Nacional de La Plata, Argentina.

"Cornaglia Fernández, J. (2014). Análisis zooarqueológico del sitio Laguna El Doce (Depto. Gral. López, Sta. Fe, Argentina). Revista Chilena de Antropología, 30(2), 24-29.

" David, B. (1990). How was this bone burnt? En S. Solomon, I. Davidson y D. Watson (Eds.), Problem Solving in Taphonomy: Archaeological and Paleontological Studies from Europe, Africa and Oceania, Volumen II (pp. 65-79). Queensland: Queensland University. 
»David, E. (2007). Technology on bone and antler industries: a relevant methodology for characterizing early post-glacial societies (9th-8th millennium BC). En C. Gates St-Pierre y R. B. Walker (Eds.), Bones as Tools: Current Methods and Interpretations in Worked Bone Studies (pp. 35-50). Oxford: BAR International Series 1622, Archaeopress.

»Escosteguy, P., Salemme, M. y González, M. I. (2012). Myocastor coypus (“coipo”, Rodentia, Mammalia) como recurso en los humedales de la Pampa boanerense: patrones de explotación. Revista del Museo de Antropología, 5, 13-30.

»Escosteguy, P., González, M. I. y Frère M. M. (2015). Nuevos datos sobre fauna menor de la Depresión del río Salado (provincia de Buenos Aires, Argentina: el caso de San Ramón 7. Archaeofauna, 24, 295-313.

» Fernández-Jalvo, Y. y Andrews, P. (2003). Experimental effects of water abrasion on bone fragments. Journal of Taphonomy, 1(3), 147-163.

» Frontini, R. (2012). El aprovechamiento de animales en valles fluviales y lagunas del sur bonaerense durante el Holoceno. (Tesis Doctoral inédita), Universidad de Buenos Aires, Argentina.

»Gallego, M. (2002). Evaluación de los procesos de formación y transformación del registro arqueológico en ambientes lagunares del Noroeste bonaerense. (Tesis de Licenciatura inédita), Universidad Nacional de Rosario, Argentina.

" Grayson, D. (1984). Quantitative Zooarchaeology: Topics in the Analysis of Archaeological Faunas. Orlando: Academic Press.

»Grayson, D. (1991). Alpine faunas from the White Mountains, California: Adaptative change in the late prehistoric Great Basin? Journal of Archaeological Science, 18, 483-506.

»Gutiérrez, M. A. (2006). Efectos, agentes y procesos tafonómicos en el área Interserrana Bonaerense. Relaciones de la Sociedad Argentina de Antropología, XXXI, 201-228.

» Gutiérrez, M. A. y Kaufmann, C. A. (2007). Criteria for the identification of formation processes in guanaco (Lama guanicoe) bone assemblages in fluvial-lacustrine environments. Journal of Taphonomy, 5(4), 151-176.

» Gutiérrez, M. A. y Martínez, G. (2008). Trends in the faunal human exploitation during the Late Pleistocene and Early Holocene in the Pampean Region (Argentina). Quaternary International, 191, 53-68.

» Hammer, Ø. y Harper, D. (2006). Paleontological Data Analysis. Oxford: Blackwell Publishing.

» Haynes, G. (1980). Evidence of carnivore gnawing on Pleistocene and recent mammalian bones. Paleobiology, 6, 341-351.

» Johnson, E. (1985). Current developments in bone technology. En M. B. Schiffer (Ed.), Advances in Archaeological Method and Theory (Volume 8) (pp. 157-235). Nueva York: Academic Press.

» Klein, R. G. y Cruz-Uribe, K. (1984). The Analysis of Animal Bones from Archaeological Sites. Chicago: University of Chicago Press.

» López González, F., Grandal-d’Ánglade, A. y Vidal-Romaní, J. R. (2006). Deciphering bone depositional sequences in caves through the study of manganese coatings. Journal of Archaeological Science, 33, 707-717.

» Loponte, D., Acosta, A. y Musali, J. (2006). Complexity among hunter gatherers from the Pampean región, South America. En C. Grier, J. Kim y J. Uchiyama (Eds.), Beyond Affluent Foragers: Rethinking Hunter-Gatherer Complexity (pp. 106-125). Oxbow: Oxford Bos.

» Lyman, R. L. (1992). Anatomical Considerations of Utility Curves in Zooarchaeology. Journal of Achaeological Science, 19, 7-22. 
» Lyman, R. L. (1994). Vertebrate Taphonomy. Cambridge: Cambridge University Press.

» Lyman, R. L. (2008). Quantitative Paleozoology. Cambridge: Cambridge University Press.

» Magurran, A. E. (1988). Ecological Diversity and Its Measurement. Londres: Croom Helm.

» Marean, C. W. y Ehrhardt, C. L. (1995). Paleoanthropological and paleoecological implications of the taphonomy of a sabertooth's den. Journal of Human Evolution, 29(6), 515-547.

» Martínez, G. (2008-2009). Arqueología del curso inferior del río Colorado: estado actual del conocimiento e implicaciones para la dinámica poblacional de cazadoresrecolectores pampeano-patagónicos. Cazadores Recolectores del Cono Sur. Revista de Arqueología, 3, 71-92.

» Martínez, G. y Gutiérrez, M. A. (2004). Tendencias en la explotación humana de la fauna durante el Pleistoceno final y Holoceno en la Región Pampeana (Argentina). En G. Mengoni Goñalons (Ed.), Zooarchaeology of South America (pp. 81-98). Oxford: BAR International Series 1298, Archaeopress.

» Massigoge, A. (2007). Procesos de formación del registro arqueológico en el sitio Cortaderas (partido de San Cayetano, provincia de Buenos Aires). Intersecciones en Antropología, 8, 197-214

» Menéndez, L, Pérez, I., Pucciarelli, H., Bonomo, M., Messineo, P., González, M. y Politis, G. (2015). Early Holocene human remains from the Argentinean Pampas: Cranial variation in South America and the American peopling. PaleoAmerica, 1(3), 251-265.

" Mengoni Goñalons, G. (1999). Cazadores de Guanaco de la Estepa Patagónica. Buenos Aires: Sociedad Argentina de Antropología.

» Messineo, P. (2011). Investigaciones arqueológicas en la cuenca superior del Arroyo Tapalqué. Un modelo de ocupación humana para el centro de la subregión Pampa Húmeda durante el Holoceno tardío. Intersecciones en Antropología, 12, 275-291.

» Messineo, P., González, M. y Álvarez, M. C. (2017). Las ocupaciones humanas durante el Holoceno temprano y medio en el noroeste de la provincia de Buenos Aires: estado actual de las investigaciones en la localidad arqueológica Laguna de los Pampas (partido de Lincon). Manuscrito inédito.

» Miotti, L. y Salemme, M. (1999). Biodiversity, taxonomic richness and specialistsgeneralists during Late Pleistocene/Early Holocene times in Pampa and Patagonia (Argentina, Southern South America). Quaternary International, 53/54, 53-68.

» Morales, N. (2015). Estudio de modificaciones de la superficie ósea en restos faunísticos del sector sur del área ecotonal húmedo-seca pampeana. El sitio San Martín 1 como caso de estudio. Comechingonia, 19(2), 323-345.

» Nilssen, P. (2000). An actualistic butchery study in South Africa and its implications for reconstructing hominid strategies of carcass acquisition and butchery in the upper Pleistocene and Plio-Pleistocene. (Tesis Doctoral inédita), Cape Town University, Sudáfrica.

» Oliva, F., Algrain, M., Ávila, D. y Gallego, M. (2004). Arqueología de la Laguna Salalé (Provincia de Buenos Aires): una aproximación a partir del análisis de los materiales líticos. En C. Gradín y F. Oliva (Eds.), La Región Pampeana. Su Pasado Arqueológico (pp. 377-387). Rosario: Editorial Laborde.

» Oliva, F., Paniza, M. C., Catella, L., Moirano, J., Morales, N., Algrain, M., Devoto, G., Ianelli, L., Oliva, C., Pereyra, B. y Sfeir, A. (2015). La construcción del pasado arqueológico en diferentes sectores del Área Ecotonal Húmedo-Seca Pampeana. Investigación y extensión desde el Centro de Estudios Arqueológicos Regionales. Revista de Antropología del Museo de Entre Ríos, 1(2), 91-102. 
» Olsen, S. y Shipman, P. (1988). Surface modification on bone: trampling versus butchery. Journal of Archaeological Science, 15, 535-553.

»Politis, G. (1984). Arqueología del área Interserrana Bonaerense. (Tesis Doctoral inédita), Universidad Nacional de La Plata, Argentina.

»Politis, G. y Salemme, M. (1990). Pre-Hispanic mammal explotation and hunting strategies in the Eastern Pampas Subregion of Argentina. En L. B. Davis y B. O. K. Reeves (Eds.), Hunters of the Recent Past (pp. 352-372). Londres: Unwin.

» Politis, G., Messineo, P., González, M. E., Álvarez, M. C. y Favier Dubois, C. (2012). Primeros resultados de las investigaciones en el sitio Laguna de los Pampas (partido de Lincoln, provincia de Buenos Aires). Relaciones de la Sociedad Argentina de Antropología, XXXVII(2), 463-472.

»Quintana, C. A. y Mazzanti, D. (2001). Selección y aprovechamiento de recursos faunísticos. En D. Mazzanti y C. A. Quintana (Eds.), Cueva Tixi: Cazadores y Recolectores de las Sierras de Tandilia Oriental. Geología, Paleontología y Zooarqueología. (Publicación Especial 1) (pp. 181-209). Mar del Plata: Laboratorio de Arqueología, Universidad Nacional de Mar del Plata.

»Quintana, C. A. y Mazzanti, D. (2010). Caza menor en sitios arqueológicos de Tandilia oriental. En M. Gutiérrez, M. De Nigris, P. Fernández, M. Giardina, A. Gil, A. Izeta, G. Neme y H. Yacobaccio (Eds.), Zooarqueología a Principios del Siglo XXI. Aportes Teóricos, Metodológicos y Casos de Estudio (pp. 307-319). Ayacucho: Libros del Espinillo.

"Scheifler, N. y Messineo, P. (2016). Exploitation of faunal resources by hunter-gatherers in the center of the Pampa grasslands during the Holocene: The archaeofauna of the Laguna Cabeza de Buey 2 site (San Carlos de Bolivar, Buenos Aires, Argentina). Quaternary International, 391, 61-73.

"Scheifler, N., Messineo, P.y Antiñir, A. 2017. Cazadores-recolectores en el sistema lagunar Hinojo-Las Tunas (región pampeana, área Oeste) durante el Holoceno temprano/medio y tardío. Primeros resultados de las investigaciones arqueológicas. Manuscrito inédito.

"Scheinsohn, V. (2010). Hearts and Bones: Bone Raw Material Exploitation in Tierra del Fuego. Oxford: BAR International Series 2024, Archaeopress.

»Stahl, P. W. (1996). The recovery and interpretation of microvertebrate bone assemblages from archaeological contexts. Journal of Archaeological Method and Theory, 3, 31-75.

»Stoessel, L. y Martínez, G. (2014). El proceso de intensificación en la transición pampeano-patagónica oriental. Discusión y perspectivas comparativas con regiones aledañas. Comechingonia, 18, 65-94.

»Vecchi, R., Frontini, R. y Bayón, C. (2013). Paso Vanoli: una instalación del Holoceno tardío en valles fluviales del sudoeste bonaerense. Revista del Museo de La Plata, 13(87), 77-93.

"Wolverton, S. (2002). NISP : MNE and \%whole in analysis of prehistoric carcass exploitation. North American Archaeologist, 23(2), 58-100. 